\title{
Os contornos tardo-modernos do sofrimento e do adoecimento psíquico: proposições éticas para o Centro de Atenção Psicossocial
}

The contours of late-modern suffering and mental illness: ethical propositions for the Psychosocial Care Center

Los contornos de la modernidad tardía sufrimiento y la enfermedad mental: las proposiciones éticas para el Centro de Atención Psicosocial

\author{
Patrícia Mendes Lemos ${ }^{*}$ \\ José Célio Freire*
}

\begin{abstract}
Resumo
Este artigo pretende realizar uma leitura do sofrimento e do adoecimento psíquicos com base no contexto social tardo-moderno. Tem o objetivo de refletir sobre as demandas apresentadas pelos usuários do Centro de Atenção Psicossocial, as quais caracterizam o sujeito contemporâneo e exigem dos profissionais e dos dispositivos da Reforma Psiquiátrica uma ética singular, para além da invenção de formas diferentes de institucionalização. Por meio do desenvolvimento de uma discussão conceitual, tomamos a loucura como sinônimo de alteridade, entendendo o próprio sofrimento como consequência do alheamento ao outro presente na vida tardo-moderna. Levando em conta a alteridade como aspecto constituinte de nossa subjetividade, inferimos com a proposição premente da revisão de saberes e práticas atuais no campo da saúde mental, o qual se pode lograr unicamente pela criação de uma nova ética que esteja ancorada na afecção pelo sofrimento do outrolouco-alteridade.
\end{abstract}

Palavras-chave: sofrimento e adoecimento psíquicos; Centro de Atenção Psicossocial; modernidade tardia; ética; alteridade.

\begin{abstract}
This article seeks to develop a reading of mental suffering and illness based on the late-modern social context. It aims at reflecting on the demands presented by the users of the Center for Psychosocial Care, which characterize the contemporary subject and require a singular
\end{abstract}

\footnotetext{
Mestranda em Psicologia pela Universidade Federal do Ceará, psicóloga. E-mail: ptmenl_78@hotmail.com.
}

** Doutor em Psicologia (Universidade de São Paulo), professor associado do Departamento de Psicologia da Universidade Federal do Ceará. E-mail: jcfreire@ufc.br. 
ethics from professionals and devices of the Psychiatric Reform, apart from the invention of different forms of institutionalization. Through the development of a conceptual discussion, we take madness as synonymous with alterity, as we understand suffering as consequence of this alienation from others in late-modern life. Taking into account the aspect of alterity as constitutive of our subjectivity, we conclude with the urgent proposition of reviewing current knowledge and practices in the field of Mental Health, which can be accomplished only by creating a new ethics that is rooted in the affection by the suffering of other-crazyotherness.

Keywords: psychological suffering and illness; Psychosocial Care Center; late modernity; ethics; alterity.

\section{Resumen}

Este artículo pretende desarrollar una lectura del sufrimiento y de la enfermedad mental desde el contexto social de la modernidad tardía. Tiene como objetivo reflexionar sobre las demandas presentadas por el Centro de Atención Psicosocial, que caracterizan el sujeto contemporáneo, y exigen de los profesionales y de los dispositivos de la Reforma Psiquiátrica una ética singular, más allá de la invención de diferentes formas de institucionalización. A través del desarrollo de una discusión conceptual, tomamos la locura como sinónimo de alteridad, entendiendo su sufrimiento como consecuencia de esta enajenación al otro en la vida de la modernidad tardía. Teniendo en cuenta el aspecto de la alteridad como constitutiva de nuestra subjetividad, infiere la propuesta urgente de revisión de los conocimientos y prácticas actuales en el campo de la salud mental, que sólo se puede lograr mediante la creación de una nueva ética basada en la alteración provocada por el sufrimiento del otro-loco-alteridad.

Palabras clave: trastornos psicológicos y enfermedad; el Centro de Atención Psicosocial; modernidad tardía; ética; alteridad.

7 emos como intenção, neste artigo, realizar uma discussão teórica acerca do sofrimento e do adoecimento psíquicos no contexto da modernidade tardia, com vistas à proposição de uma ética para o Centro de Atenção Psicossocial (Caps), tomando este último como dispositivo de atuação referente às questôes de saúde mental e resultante do processo social de Reforma Psiquiátrica. 
Para tanto, traçamos as condiçôes para refletir o contexto sociocultural em que a subjetividade, o sofrimento e o adoecimento psíquico se inscrevem, para, em seguida, definir essas categorias em suas peculiaridades e atualidades, e, por fim, como efeito necessário desse processo, apontar proposiçôes éticas em consonância com as demandas emergentes do Centro de Atenção Psicossocial. ${ }^{1}$

Como disciplina imprescindível às práticas de saúde mental (SM), a Psicologia requer, cada vez mais, um conhecimento aprofundado do psiquismo humano e a criação e a implantação de técnicas interventivas capazes de responder às demandas encontradas nesse campo (Lemos \& Cavalcante Júnior, 2009). Considerando que tais demandas encontradas na saúde mental estão permeadas pela experiência de sofrimento e frequentemente se referem a quadros psicológicos considerados disfuncionais ou (psico)patológicos, torna-se relevante enfatizar os aspectos culturais e sociais na constituição dessas, visto que o que leva um usuário a buscar auxílio na tentativa de compreender sua realidade subjetiva não pode ser pensado separadamente de sua inserção no mundo social contemporâneo (Moreira, 2004).

Contrapondo-se ao conceito de Pós-modernidade, que implicaria uma possível superação da Modernidade, Lipovetsky (2007) dá-nos a conhecer o conceito de Hipermodernidade, indicativo do ponto extremo da Modernidade. Para o autor, situamo-nos na sociedade do excesso, da velocidade, da aceleração absoluta. O sujeito hipermoderno constitui aquele que vivencia o mais e o menos ao mesmo instante, inserido num mundo onde o público e o privado não se distinguem e onde a liberdade incorre num alto custo: o da frustração. Diferentemente da Modernidade, que punha em evidência a crença num futuro perfeito por meio do progresso e das suas utopias revolucionárias, a Hipermodernidade assinala novos mitos e utopias: do corpo perfeito, da alimentação natural, da moda como fator democrático de satisfação, da interação entre os diferentes, entre outros. Não obstante, a ênfase na diferença não impede a disseminação de uma indiferença exagerada.

\footnotetext{
Os Caps constituíram-se como dispositivos substitutos do modelo asilar a partir do processo de reforma psiquiátrica no país. Conforme Ribeiro (2004), estes serviços variam na intensidade dos cuidados às pessoas com transtornos mentais, bem como na diversidade de terapêuticas oferecidas no atendimento interdisciplinar. Destinam-se àqueles que, pela doença e condições de vida, necessitam mais que um atendimento ambulatorial, possuindo uma demanda para acompanhamento continuado. Devem oferecer um cuidado ampliado, de modo a propiciar uma forte sustentação cotidiana na lida com o paciente, incluindo suas relações sociais. As dificuldades concretas de vida dos usuários, em decorrência de seu adoecimento, devem ser incorporadas pela atenção à saúde mental, diferentemente do modelo asilar anterior em que esses aspectos eram considerados como fatores "extraclínicos", tornando-se dissociados do tratamento, sendo dirigidos a outras instituições ou setores.
} 
Apontando-nos os paradoxos de uma sociedade da decepção, Lipovetsky (2007, p. 5-6) discorre:

Enquanto os grupos ou categorias sociais vinculados às tradições conseguem harmonizar de forma mais ou menos bem-sucedida seus anseios respectivos, restringindo assim a amplitude da decepção experimentada, os grupos ou categorias hipermodernos emergem como sociedades de decepção inflacionada. Quando a felicidade é prometida a todos e os prazeres são enaltecidos em cada esquina, a vida cotidiana está passando por uma dura prova. Além disso, a "qualidade de vida" em todos os campos da atividade humana (vida conjugal, vida sexual, alimentação, moradia, meio ambiente, lazeres, etc.) passou a ser o novo horizonte das expectativas individuais [...]. Quanto mais os imperativos do bemestar e do bem-viver são fixados como meta imprescindível, mais intransitáveis se tornam as alamedas do desapontamento [...]. Após a "cultura do aviltamento" e a "cultura da culpabilidade" (que assim foram analisadas por Ruth Benedict), temos agora o tempo das culturas da ansiedade, da frustração e da decepção. (grifo nosso)

Mas antes mesmo de despontar com suas reflexões que dão ênfase ao teor de frustração característico das sociedades atuais, Lipovetsky (2005), em sua obra $A$ sociedade pós-moralista: o crepúsculo do dever e a ética indolor dos tempos democráticos, focava-se numa análise ética da Hipermodernidade, a qual nos soa de grande valia. Nesta, denota o aparecimento de novos dilemas e o retorno de velhos conflitos, mas sem a antiga apologia ao sacrifício das sociedades tradicionais, nas quais havia obrigações inquestionáveis (com o trabalho, a pátria, a família). Os valores, que não desvaneceram, mas se transformaram, recaem agora sob a égide de uma ética supostamente capaz de conciliar os interesses individuais com os da sociedade.

A ética na sociedade dita pós-moralista, longe da ideia do dever absoluto e inquestionável (associado à religião), difunde-se por meio do desejo por regulamentaçôes, regras justas e "especialistas" de todas as ordens, mas sem requerer a renúncia pessoal, as imposições e os "fiscais da moral” de outrora. Falase em qualidade de vida e direitos subjetivos, sem a exigência da virtuosidade. O sentido do dever é amenizado e não há mais a noção de sacrifício pelo outro. Tanto o mal como os bons sentimentos são transformados em espetáculo como consequência da última fase da cultura democrática individualista, em que ocorre uma relativização da ética, abrindo espaço para a contradição e a supremacia de uma moral indolor, que não pesa ao indivíduo nem se atrela a concepções de moralidade ou de imoralidade (Lipovetsky, 2005). 
No intuito de delinearmos os contornos do sofrimento e do adoecimento psíquicos na contemporaneidade, apropriamo-nos também da definição de Giddens (2002) acerca da Modernidade tardia como o estágio avançado da Modernidade liberal, cuja caracterização das sociedades humanas dá-se por um funcionamento globalizado e pelo desenvolvimento de um modelo cultural narcisista (Freire, 2001). O eu, como constituição subjetiva, na perspectiva de Giddens (2002), está inserido no mundo moderno tardio, o qual é caracterizado por uma interconexão entre dois extremos: as disposiçõos pessoais e as influências globalizantes. Esse eu precisa ser construído reflexivamente, ou seja, ser capaz de imprimir uma crítica sobre si mesmo, numa "cultura de risco", na qual a influência de acontecimentos distantes sobre eventos próximos ameaça a sua integridade, a sua intimidade, ocorrendo uma consequente ausência de sentido pessoal e exigindo uma reorganização psíquica. Nesse contexto, a doença mental também poderia ideologicamente ser compreendida como um risco acarretado pela vida moderna, levando em conta o processo social de construção da loucura.

Pautamo-nos, portanto, na análise de Giddens (2002) sobre aquilo que nomeia como Modernidade "alta" ou "tardia" e sua relação com a construção reflexiva do eu em meio a uma imprevisível miríade de possibilidades de escolha para os sujeitos em seus diversos aspectos de vida social, pessoal, familiar, íntima. A ênfase do autor em apontar a emergência de novos mecanismos de autoidentidade, os quais constituem e são constituídos pelas instituições da Modernidade, contribui para a compreensão do eu como uma entidade ativa, uma vez que os indivíduos, atravessados pelos mecanismos de desencaixe ou sistemas abstratos, ${ }^{2}$ criam suas autoidentidades e promovem influências sociais de consequências globais, ainda que atuem em contextos locais e específicos de ação.

Nessa perspectiva, Giddens (2002) apresenta as noções de confiança e risco com uma aplicação peculiar e impactante para a constituição do eu. A primeira, definida como fenômeno genérico fundamental para o desenvolvimento da personalidade, relaciona-se a um "senso precoce de segurança ontológica”, uma espécie de proteção que permite a interação do eu com a realidade cotidiana através da suspensão de potenciais ameaças, as quais poderiam levar a uma paralisia da vontade, caso fossem tomadas

\footnotetext{
Estes consistem nas "fichas simbólicas" somadas aos "sistemas especializados". As primeiras dizem respeito aos meios de troca intercambiáveis em múltiplos contextos, com um valor padrão, como o dinheiro, por exemplo. No segundo caso, o autor se refere à disposição de modos de conhecimento técnico, de validade reconhecida, os quais penetram em todos os aspectos da vida social, estendendo-se desde as áreas tecnológicas às intimidades do eu (Giddens, 2002).
} 
diretamente, impedindo os indivíduos de um envolvimento efetivo com sua realidade no nível prático de suas ações.

A noção de risco remete à ideia de uma sociedade em que se tem de viver com base em atitudes de previsibilidade e cálculo devido à enorme quantidade de possibilidades de ação, sejam estas positivas ou negativas, que confrontam de modo contínuo, individual e globalmente, a existência social contemporânea. Estarmos inseridos numa cultura de risco não corresponde a dizer meramente que a vida social seja mais arriscada, mas que o risco representa um conceito pelo qual leigos e especialistas organizam o seu mundo social. Os sistemas abstratos, ao se instalarem na vida cotidiana, juntamente com a dinamicidade do conhecimento humano, resultam na infiltração da consciência do risco nas ações de todas as pessoas. Para ilustrar isso, tomemos o exemplo de como oportunidades individuais de vida (no mercado de trabalho, na formação acadêmica e mesmo nas relações entre as pessoas) estão atreladas à economia capitalista global - são os ambientes de risco institucionalizados estabelecendo ligação entre riscos individuais e coletivos de variadas formas (Giddens, 2002).

Giddens (2002) discorre acerca de uma repressão institucional e não pessoal de questôes de natureza moral e existencial, ou seja, a exclusão de valores e modos de comportamento potencialmente perturbadores para a população em geral, de modo que a "doença mental" assim entendida possibilita o afastamento dessas questôes da vida diária. O manicômio, por exemplo, teve essa finalidade de afastamento, representando um ambiente de correção técnica orientado para as relaçôes transformadoras da Modernidade.

No que concerne ao sofrimento psíquico contemporâneo, conforme Benasayag (2005; 2009; 2010), estamos imersos numa "cultura do risco", em que o "futuro deixou de ser uma promessa e tornou-se uma ameaça". O sofrimento psíquico das pessoas apresenta uma novidade, estando esta relacionada à época em que vivemos. A constatação desse novo elemento se apresenta em aspectos quantitativos (como a crescente demanda nos serviços de saúde mental de queixas como medo, insegurança e ansiedade) e qualitativos (elementos de cunho histórico e político). A Modernidade criou uma crença exacerbada no progresso e, com ela, a promessa de um futuro melhor, de modo que todas as atividades humanas ordenaram-se para essa crença no futuro como promessa. No entanto, vivemos a maior crise social e histórica em nossa atualidade, que se caracteriza por uma relação específica entre os aspectos global e local. Enquanto as partes que constituem o todo (sociedade), em seu estado "normal", são dotadas de autonomia, em estado de crise, essas partes perdem tal autonomia e passam a funcionar como dependentes dos fatores sociais, como se estivessem "coladas" a esses aspectos, 
sendo deles indissociáveis. O global passa a atribuir um novo sentido aos atos individuais, de forma que o que somos não depende de nós, mas de fatores externos a nós, ao mesmo tempo em que não compreendemos ou não aceitamos como essas forças externas atuam sobre nossas vidas. Essa constitui uma das causas do "novo sofrimento psíquico atual".

Para Benasayag $(2005 ; 2009 ; 2010)$, os serviços de psicologia e psiquiatria vêm sendo transbordados por novas demandas, as quais não correspondem à nosografia clássica dos transtornos mentais. Em sua percepção, estamos inseridos num mundo onde o sofrimento das pessoas é reflexo de uma crise histórica e não encontramos uma maneira viável de lidar com o negativo. $\mathrm{O}$ sofrimento se expressa de forma não discursiva e não simbólica, por meio da dor, que constitui a única maneira que o sujeito encontra de manifestar o seu desacordo com o sistema social. Ocorre uma queda no modelo "normalizador" (o homem normal seria aquele capaz de eliminar a loucura, as paixões, o negativo) na Modernidade tardia, e nós reagimos a isso com a tentativa de "abafamento" do sintoma, com a destruição da singularidade, criando a ilusão de que não há mais sofrimento existencial, apenas patológico. Ao mesmo instante em que as pessoas experimentam cada vez mais que suas vidas dependem de coisas que não podem controlar (desemprego, mídia, desastres ecológicos, economia), numa sociedade que não tolera a dor (porque quanto mais se sofre mais se tem de estar bem), os profissionais são convocados a normalizar as expressões do sofrimento, buscando suas razões endógenas, de modo a individualizar a subjetividade e constatando, inevitavelmente, sua impotência frente a esses novos modos de sofrer (Moreira, 2004; 2009).

A "perda da alma" característica do homem moderno, tal como reflete Kristeva (2002), denota a existência de um novo paciente/usuário/cliente que traz em sua queixa um sofrimento preso ao corpo (somatização) e o faz comprazendo-se nessa mesma queixa, a qual ele deseja insistentemente. Não lhe oferecendo alternativas, a não ser a neuroquímica (na qual se torna possível encontrar alívio para insônias, depressões, surtos psicóticos, etc.), a sociedade que formou esse homem moderno, ao mesmo tempo, subtraiu-lhe a alma, tornando sua expressão padronizada e seu discurso normatizado.

O espetáculo de imagens ofertado pela sociedade captura as angústias e os desejos, de modo que a vida psíquica do homem moderno situa-se no intervalo entre os sintomas somáticos e a transformação de seus desejos em imagens. O mundo desse homem satisfeito com "pílulas e telas" está permeado de dificuldades relacionais e sexuais, "somatizaçôes" de toda ordem e uma quase total impossibilidade de expressão do mal-estar, estando sua linguagem revestida por uma camada de artificialização, sentida como vazia e robotizada. 
A ausência de representação psíquica passa a ser o aspecto comum a todas as novas sintomatologias, a qual poderá manifestar-se por meio de um "mutismo psíquico" ou de variados sinais tidos como artificiais ou vazios, implicando necessariamente um entrave para a vida sensorial, sexual, intelectual, podendo trazer prejuízos ao próprio funcionamento biológico. Assim expressas, as novas doenças da alma referem-se às dificuldades ou incapacidades de representação psíquica que podem chegar a matar o espaço psíquico, requerendo eminentemente a descoberta dessa nova psique manifesta na contemporaneidade (Kristeva, 2002).

Para pensarmos acerca da (psico)patologia, resgatamos a proposta epistemológica e de intervenção apresentada por Moreira (2009), de uma psicopatologia crítica, a qual transcende a Psicologia individualista, ao redimensionar a definição da doença mental como atribuída unicamente à realidade interna do indivíduo. A psicopatologia passa a ser entendida, nesse ponto de vista, como "mutuamente constituída em seus múltiplos contornos", de modo a considerar não apenas os processos biológicos e psicológicos, mas também históricos, sociais, políticos, antropológicos, ou seja, culturalmente produzidos de processos ideológicos. Conforme a autora, vivemos numa sociedade ocidental marcadamente hedonista, na qual prevalece o culto ao prazer. Nessa ordem de pensamento, o sofrimento é algo a ser eliminado, de forma rápida, pois o homem contemporâneo não suporta sofrer, o que provoca a experiência de vazio.

Desse modo, a contemporaneidade, de forma geral, convive com múltiplos paradigmas de psicopatologia, preservando uma dominância do modelo biomédico, que enfatiza a técnica e os procedimentos nas formas de tratamento da doença mental. O predomínio da técnica e da medicalização é resultado das consequências do estilo de vida capitalista produzido pelo contexto cultural tardo-moderno, em que, nos últimos 50 anos, ocorreu o declínio das clássicas configurações neuróticas (fobias, histerias e desordens obsessivas) e a elevação de desordens de personalidade (narcísica, depressiva, antissocial e borderline). Esse fenômeno aponta para a ideia de que os sintomas atribuídos a aspectos existenciais, orgânicos ou unicamente psicológicos podem ter suas raízes sociais no mundo capitalista contemporâneo, no qual prevalece o "nervosismo" pela permanente crise da identidade.

Moreira e Sloan (2002) analisam as consequências do individualismo capitalista no mundo contemporâneo ocidental, apresentando os efeitos disso relacionados à autoestima (por meio da forma de se lidar com as frustrações, os medos e com os desejos que a própria sociedade instaura) numa sociedade narcísica, individualista e despotencializadora, que exige, em máximo grau, 
um homem autônomo, belo e bem-sucedido. Nessa sociedade, ocorre uma ideologia que é dada pelo sustento a um amplo mercado estabelecido em torno do sofrimento psíquico. $\mathrm{O}$ individualismo de perfil narcisista desemboca num narcisismo novo, trançando uma configuração inédita do indivíduo em suas relações consigo e com o mundo; o individualismo puro, desprovido de valores sociais e morais. Na depressão, por exemplo, o self individualizado tende a personalizar estados internos de emoção, incluindo angústias decorrentes de eventos sofríveis da vida. Por outro lado, como resultante do estilo de vida consumista, ocorre uma deterioração das relaçôes interpessoais, corroborando para a crise do suporte social, trazendo severas consequências para a evolução dos quadros patológicos relacionados às sociedades individualistas (Moreira \& Sloan, 2002).

Homem (2003), por sua vez, afirma que a contemporaneidade tem um aspecto de descartabilidade em que o sujeito obriga-se a assumir uma vinculação a diversos objetos, desvinculando-se do próprio desejo e colocando-se no lugar de não ser. Nesse sentido, esse sujeito acaba por tornar-se alvo fácil dos discursos medicalizantes e medicamentosos, formas ilusoriamente sustentadas pela ciência moderna. O sujeito constitui um consumidor obediente e submisso, preso aos modelos identificatórios da indústria cultural. A ciência e a tecnologia viabilizam a geração de uma diversidade de objetos novos e avançados, levando à mercantilização de todos os domínios da experiência humana, incluindo a saúde e a patologia. A “alma” está aquietada por psicofármacos cada vez mais eficazes na domesticação do medo, da tristeza, da angústia, conduzindo ao desaparecimento do sujeito por meio de sua objetivação. A submissão às práticas discursivas dominantes opera pela manutenção da dominação social do corpo e do psicológico, oferecendo ao sujeito mínimas condiçoes de atuação ante a própria existência. A medicalização excessiva é, portanto, uma consequência natural do capitalismo monopolista e financeiro que transforma tudo em valor abstrato, traduzindo também o ser em valor de troca.

Corroborando com as ideias acima, Birman (2003) denomina "cultura do somático" esta da economia do corpo ter como ponto de partida um intenso processo de medicalização. Há um excesso de consumo de medicamentos atualmente, além de as manifestações do mal-estar serem expressas de uma forma especificamente diferente: pelo mal-estar corpóreo. Patologias como depressões, pânico e compulsões tomam a corporeidade como forma de expressão, além de se evidenciarem como impossibilidades de ação na subjetividade, ou seja, como impotência. O mal-estar contemporâneo é 
expresso no corpo e na ação, de modo que a linguagem se torna empobrecida e o discurso esvazia-se de sua dimensão simbólica, o que caracteriza a expressão de dor em vez de sofrimento.

Ao imergir na dor, a subjetividade denuncia sua vertente narcísica, em que o sujeito fecha-se em si mesmo, não se dirigindo ao outro, perdendo sua dimensão de alteridade. $\mathrm{O}$ diálogo com o outro fica obstruído na expressão da patologia pela dor, uma vez que o sujeito se restringe a si em sua pretensa autossuficiência. Já no sofrimento, oposto da dor, o sujeito é capaz de dirigir ao outro uma demanda, demonstrando um caráter de atividade; diferentemente da dor, que esboça passividade. Em suma, a subjetividade contemporânea parece não expressar sua capacidade de transformar dor em sofrimento, tornando-se vazia num mundo sem mediação e sem sentido (Birman, 2003).

Pensamos, então, a reorientação do modelo de atenção em saúde mental como uma mudança que demanda investimentos políticos, técnicos, financeiros e, no que nos interessa aqui, éticos. No entanto, em sua práxis, os profissionais têm uma trajetória como trabalhadores tradicionais, estando sua atuação caracterizada por concepções advindas do modelo hegemônico, cujo centro da atenção é o indivíduo e sua doença, estando as suas ações, portanto, desvinculadas do contexto de vida concreto dos usuários e fundamentadas no conhecimento decorrente da própria prática e do senso comum (Hirdes, 2009).

Conforme Hirdes (2009), como ainda não são exploradas as contradições das práticas, os profissionais estão operando em posições ambíguas, vivendo uma cidadania dissociada da vivência e da organização do trabalho, ao mesmo tempo em que experimentam a alienação em relação aos seus fazeres, a restrição da atenção psicossocial e da liberdade, em que a medicalização assume o papel estruturante de todas as práticas, sendo o instrumento primeiro da abordagem terapêutica. Nos serviços de saúde mental da rede extra-hospitalar, o processo de reforma está centrado primordialmente no aspecto administrativo, e as dimensões técnicas, políticas e éticas estão relegadas a uma parcela mínima de trabalhadores. O compromisso ético dos profissionais com o processo de reforma está menos associado ao conhecimento do processo histórico-político do que com uma questão pessoal, evidenciando uma lacuna entre o referencial teórico arcaico e um novo referencial, ainda incipiente em sua concretização.

Hirdes (2009), ao propor uma revisão teórica do processo de reforma psiquiátrica, aponta ainda a importância da realização de uma análise crítica dos serviços substitutivos, uma vez que estes assumem um peso até maior para a vida dos pacientes do que as variáveis clínicas que interferem no adoecimento 
e em sua evolução. Nesse sentido, serviços como os Centros de Atenção Psicossocial (Caps) deverão constituir-se enquanto lugares de passagem, de forma a não caminhem para uma nova institucionalização. Ainda que os projetos de reforma não sejam homogêneos, podem existir princípios gerais orientadores, mas estes estão, em última instância, submetidos aos lócus específicos onde as práticas se dão, as quais são desenvolvidas de acordo com as concepções teóricas dos trabalhadores de saúde mental.

Nesse ponto da discussão, questionamos o papel desinstitucionalizador dos Caps, pois uma proposta de desinstitucionalização que se dê pela via da criação de novas instituiçôes soa-nos como uma questão por demais contraditória ou pelo menos incompleta, requerendo uma necessária revisão ética do lugar que ocupa no contexto tardo-moderno e dos seus modos de atuação.

Apontemos aqui a discussão realizada por Caponi (2009) acerca da reflexão foucaultiana, não mais sobre a instituição com sua regularidade e suas regras, mas sobre os desequilíbrios de poder. Conforme a autora, a psiquiatria carrega consigo a especificidade da ausência de um corpo, ${ }^{3}$ de modo que, ao contrário das outras áreas da medicina, a precisão nosológica não assume tanta importância (em outras áreas médicas, essa precisão é sempre fundamental para a realização do diagnóstico diferencial; por exemplo, uma úlcera será invariavelmente diferente de um câncer de pulmão) quanto investigar se o paciente trata-se ou não de um louco. O diagnóstico da loucura estabelece-se, portanto, neste campo dual; não é essa preocupação por determinar a lesão, própria da neurologia, de que se ocupa o psiquiatra, este último não deseja saber se dizer determinadas coisas, ouvir vozes, estar melancólico associa-se a esta ou àquela lesão, mas se isso caracteriza ou não a loucura.

Para tanto, o poder da psiquiatria se vale, em tempos de reforma, da busca por tornar explícito aquilo que se esconde por trás dos hábitos, das condutas, dos humores, da história de vida, dos antecedentes familiares. Essa é a função do interrogatório: disciplinar, atribuir ao sujeito uma identidade. Ao psiquiatra cabe descobrir dados que falem de condutas e reações anormais, anteriores mesmo ao aparecimento da doença, ou melhor, saber quais os signos que funcionam como condição de possibilidade para o surgimento da loucura. $\mathrm{O}$ interrogatório, por assim dizer, possibilita o reconhecimento do doente como louco e, ainda, o reconhecimento do próprio saber psiquiátrico. Sua lógica deve, portanto, ser compreendida no interior das estratégias e mecânicas de poder (a ideia de anormalidade, o estabelecimento de faltas e a atribuição da

\footnotetext{
3 Consultar o artigo intitulado Michel Foucault e a persistência do poder psiquiátrico, em que a autora (Caponi, 2009) esclarece, de modo mais aprofundado, a questão da ausência do corpo em psiquiatria, com base nos estudos de Michel Foucault.
} 
loucura ao outro) através das quais esse saber se afirma. O lugar da psiquiatria é esse em que se confrontam a vontade perturbada, as paixões indóceis, as condutas incômodas do louco e a retidão moral socialmente desejada, que se estabelece sob o eixo "paixão-vontade-liberdade", entre a vontade pervertida e a terapêutica dominante e sob o signo da identidade do louco e não da sua alteridade.

Entretanto, para Caponi (2009), essas estratégias de poder não se limitam ao encerramento das instituições fechadas, persistindo nos centros de atenção psicossocial a cada vez que a terapêutica se limita a esses instrumentos da psiquiatria no século XIX (o interrogatório e o uso de drogas). Se a psiquiatria deixou de ter como ordem o internamento e o encerramento, trata-se agora de medicar e dominar as paixôes, os delírios, os maus comportamentos, por meio do uso de psicofármacos. A esse respeito, a autora discorre:

Em lugar de docilizar pelo encerramento físico manicomial, dociliza-se pelo encerramento químico, pelo isolamento que impõe o uso de psicofármacos que modelam os hábitos e as condutas, que dominam os pensamentos e os delírios, que minimizam o risco de violência, mas que, ao mesmo tempo, exigem um custo muito elevado. $\mathrm{O}$ custo de perpetuar a ideia da psiquiatria clássica de "ausência do corpo do louco". Só quando imaginamos essa ausência de corpo podemos compreender que sejam legitimados e minimizados os graves efeitos secundários e indesejados dessas drogas, tais como a impotência, o sono e fadiga permanente, a dor física, a insensibilidade corporal (Caponi, 2009, p. 102-103).

Entendemos ser primordial redimensionar o dispositivo psiquiátrico e clínico em seus paradigmas constituintes e em suas técnicas de poder/ saber, compreendendo a genealogia do sujeito da saúde mental para podermos pensá-lo não como algo dado, mas como uma produção subjetiva configurada como doença mental que recai sobre corpos institucionalizados. Esse redimensionamento implica em não interpretar a loucura como erro, inferioridade, incapacidade; ao contrário, potencializá-la como diferença, um novo modo de assumir relações com o mundo, tomando o saber como possibilidade e invenção de subjetividades para além de uma técnica de normatização, onde o diagnóstico passa a ser entendido como tomada compartilhada de responsabilidades, efetuando o rompimento da hierarquia médico-paciente. $\mathrm{O}$ redimensionamento tornou-se necessário porque a psiquiatria separou o "objeto fictício" (doença) da existência concreta dos usuários e do corpo social no qual se inserem e pelo qual são constituídos (Torre \& Amarante, 2001). 
A técnica, o saber científico, a normatividade, a especialização dos saberes, enfim, os diversos dispositivos que operam por meio das instituições, ocultam, para Gadamer (2006), as questões vitais sobre a saúde e a doença, as quais dizem da tensão presente em nossa civilização fundamentada pelos ditames da ciência. A ciência detém o saber sobre a doença, que é perturbação, perigo, algo com o qual se tem de lidar. A doença nesse contexto é tida como objeto, e como tal opera uma resistência à sua inserção nos acontecimentos da vida; é captada por uma objetivação que permite uma sujeição ao conhecimento nas práticas de saúde. No entanto, a doença se auto-objetiva, revelando-se como um "lançar-se contra", o "importuno". O autor se refere à imprevisibilidade, ao mistério presente no caráter oculto da saúde: a ideia de que esta não se declara por si mesma. Ou seja, a saúde não pode ser de todo mensurada, submetida a padrões genéricos, a não ser até certo ponto; há uma medida natural que as coisas carregam em si: "Se não se pode medir verdadeiramente a saúde é por ela ser um estado da adequação interna e da conformidade com si próprio, que não pode ser superado por um outro controle" (Gadamer, 2006, p. 114).

É essa harmonia não manifesta, esse caráter ocultado, que ensejamos enfatizar na reflexão ética acerca do Centro de Atenção Psicossocial, entendendo a saúde mental também como uma expressão do ritmo da vida, de um equilíbrio que sempre volta a se estabilizar, como na concepção de Gadamer (2006). Ao tomarmos o horizonte do segredo da saúde, não temos a pretensão de desvelálo, mas a motivação para reconhecê-lo e evidenciar sua relevância na intenção ética de estabelecer um compromisso com a desconstrução de dispositivos e técnicas que, durante muito tempo, legitimaram (e ainda legitimam) práticas excludentes, institucionalizantes e opressoras de pessoas em condição de sofrimento e adoecimento mental.

Figueiredo (1995) se debruça sobre a dimensão ética dos discursos e práticas das psicologias, a qual emerge como plano da exigência de uma nova racionalidade, na direção de uma cultura pós-epistemológica. A ética assume posição central, e não mais a epistemologia, incorrendo na superação da hegemonia do pensamento representacional e da noção de verdade por correspondência ou adequação. Nesse âmbito, cada uma das diferentes doutrinas psicológicas tem uma dimensão ética, constituindo-se em dispositivos aptos a propiciar, configurar, formar, constituir os homens e seus mundos, suas experiências sociais e subjetivas; sendo ethos, ou seja, moradas e destinos para o homem. Desse modo, as teorias e sistemas psicológicos somente podem ser compreendidos no e pelo lugar que ocupam no espaço sociocultural contemporâneo. 
Em sua análise das abordagens psicológicas no contexto da Modernidade tardia, Freire $(2001 ; 2002 ; 2003)$ denuncia que a Psicologia em seu sentido amplo tem se revelado reforçadora de um modelo societário individualista e seu principal dano teria, como consequência, a anulação do outro, ${ }^{4} \mathrm{o}$ alheamento à alteridade. Essa ciência, entranhada pelas necessidades mercadológicas, promove o "ensimesmamento", o egocentrismo, em sua preocupação obsessiva com o mesmo, o mim ou o eu, criando um abismo em relação ao outro. No entanto, esse outro é o que constitui a nossa subjetividade e nos intima, nos mobiliza, nos interpela, a todo o momento, e o seu aniquilamento assume um caráter ético (Alencar \& Freire, 2007). O sujeito a ser resgatado ou encontrado pelas Psicologias deve ser aquele que tem o outro por fundamento, postulado esse constituído fundamentalmente pela dimensão ética. Conforme Freire (2002, p. 61):

Somos constituídos originalmente, em nossa subjetividade, pela alteridade radical, mas dela nos afastamos com a ingerência de modos individualizantes de ser-no-mundo [...] e assim tornamo-nos alheios ao outro, sobre o império da indiferença para com sua outridade. [...] Enquanto o mercado for, a um só tempo, o sujeito social por excelência e o destinatário de nossas açóes, estaremos distanciados de nossa própria incondição humana e da má consciência (Lévinas) de sermos para e pelo Outro.

Conforme a sociedade na qual estamos inseridos estimula-nos a uma postura cada vez mais individualista, a responsabilidade pelo Outro passa a não ter sentido para o sujeito, como apontam Freire e Moreira (2003). Para os autores, o sofrimento humano ou a psicopatologia são expressão decorrente do distanciamento do sujeito daquilo que o constitui enquanto alteridade. $\mathrm{O}$ fato de não ser (não se permitir ser) afetado pelo outro (o que nomeiam como desafeto) pode conduzir à depressão, bem como a outros transtornos psíquicos.

Ao abordar a questão do alheamento em relação ao outro, Costa (Betto; Barba \& Costa, 1997) mostra-nos como esta concerne à desqualificação do sujeito como ser moral traduzida numa atitude de distanciamento, diferindo do ódio, da rivalidade ou do temor, os quais implicam, por sua vez, numa sensação de ameaça (ante o outro) de privação de algo

\footnotetext{
O outro ou o Outro apresentar-se-ão em momentos distintos no decorrer do texto, sendo que o uso do minúsculo poderá referir-se àquilo que é diferente do eu, do mim, do mesmo, podendo ser qualquer outro, enquanto o maiúsculo terá tanto o sentido de ênfase à dimensão da alteridade, como será colocado quando, a partir da ética radical levinasiana (Lévinas, 1980; Freire, 2001; 2002; 2003), disser respeito àquilo que não seja outro homem, mas algo que remete à ideia de infinito.
} 
considerado crucial para nossas vidas. Tal alheamento repercute em não ver o outro como alguém a ser respeitado em sua integridade física e moral, como agente autônomo e potencialmente capaz de criar normas éticas e ser parceiro no seguimento das leis partilhadas.

O estado de alheamento incorre na não consciência de quem pratica a "impiedade" ou a indiferença, pois não a reconhece como tal, isso porque o objeto de sua violência, nada tendo a oferecer, não tem valor como pessoa humana, não importando, portanto, o seu sofrimento. Desse modo, podemos inferir que a indiferença é exatamente aquilo que anula o outro em sua humanidade. O "comércio da felicidade" característico da atualidade cria condições para a prática da indiferença, exigindo sempre mais dinheiro e atenção para com o si mesmo. Se isso ocorre é porque toda deficiência, falta ou privação devem ser rechaçadas a fim de evitar a presença indesejável das frustrações emocionais. Neste contexto, o outro é destituído completamente do seu valor como existente (Betto et al., 1997).

Ao tomarmos o outro como alteridade e, em nossa leitura, a alteridade como loucura, compreendemos que a indiferença ou o alheamento em relação ao louco acaba por manifestar-se, nas sociedades contemporâneas, por meio de diversos modos e sentidos, desde a criação histórica da loucura como categoria sociológica, passando pelo consequente processo social de exclusão do louco e chegando aos discursos e práticas legitimados que conferem prioridade ao diagnóstico e à medicalização, minando as possibilidades de existência deste enquanto sujeito. Nesse sentido, há que se atender ao chamado dessa "intimação ética", do qual não podemos simplesmente nos ausentar.

$\mathrm{Na}$ concepção de Freire (2003), somos intimados a realizar uma "necessária ida do eu em direção à exterioridade e uma implicação do eu pela vinda do Outro, que exige uma responsabilidade irrecusável" (2003, p. 13). Ou seja: a ética é o que permite dispor de uma resposta ao outro, na escuta ao seu sofrimento. Compreendendo-se o outro como o que é anterior ao eu, o que é inatingível, o que o afeta, não sendo possível pensar a construção de subjetividade por um processo ativo do eu sobre o outro. A ética da alteridade radical de Lévinas é-nos desvelada por Freire (2002, p. 44):

Em Lévinas, não consigo ir ao encontro do outro, pois o outro vindo de encontro a mim sempre me excede. Neste desencontro o que há é passividade em relação ao outro que me 
afeta. A saída então é entender a relação possível (não a unidade conceitual) entre seres singulares que, pela palavra, constituem a universalidade, na e pela responsabilidade (resposta ao outro). O Outro me cobra e eu devo prestar contas; só assim, pelo reconhecimento da injustiça, a justiça, vindo de fora, se faz possível. Esse "vir de fora" é a transcendência em que o Rosto do Outro nos faz face. Diz Lévinas: "O rosto que me olha me afirma".

O filósofo Emmanuel Lévinas (1980), na elaboração de sua ética da alteridade radical, realiza a crítica da redução do Outro ao mesmo, pondo em questão o exercício do mesmo. Ética significa a refutação de minha espontaneidade pela presença do Outro; ela ocorre quando a estranheza do Outro se realiza como um questionamento de minha espontaneidade, uma vez que se impõe a mim sua irredutibilidade aos meus pensamentos. Uma relação ética é não alérgica ao Outro, é aquela em que acolho o seu rosto e seu discurso. É a escuta de uma relação face a face, em que estou vulnerável e sensível a ser afetado, abalado e desconcertado profundamente pela grandeza da alteridade, que me remete ao infinito.

Sob esse olhar, em que consideramos a loucura como alteridade e apontamos a premência de uma ética singular para o Centro de Atenção Psicossocial, colocamos em questão o exercício das práxis atuais desenvolvidas e legitimadas nesse campo, as quais nos parecem ser reforçadoras do mesmo, em que a loucura está configurada ainda como uma espécie de "substrato" (neurológico, biológico, anátomofuncional) a ser institucionalizado de novas formas, demandando a própria contenção e abafamento.

Ao promover a discussão acerca das implicações da ética da alteridade radical levinasiana para o trabalho em saúde, Carvalho, Bosi e Freire (2009) definem o outro como aquele que não é passível de tematização ou conceituação, justamente por não se poder comportar em uma lógica racional, podendo ser contatado apenas pela via dos sentidos, da afetividade e da sensibilidade, o que remete à possibilidade de uma escuta ética. Os autores associam o cuidado em sua dimensão ética à noção de atenção psicossocial, ressaltando o cuidado em sua dimensão ontológica, esta que dista das acepçôes comumente ligadas ao termo assistência. O cuidado para e pelo outro como uma dimensão ética significa uma exigência de quem cuida, implicando a não imposição de um saber-poder sobre o outro, como nas práticas mais tradicionais, as quais tendem a reservá-lo uma identidade, a mantê-lo em sua mesmice, 
domesticando-o conforme preceitos institucionais. O lugar do outro, do louco, é, desse ponto de vista, o da alteridade que deve ser reconhecida como tal em vez de aniquilada (Carvalho; Bosi \& Freire, 2008).

Retomemos aqui, como ensejo de uma conclusão, uma leitura anterior (Freire, 2008) em que atentamos para os contornos tardo-modernos do sofrimen to psíquico em sua relação com o cuidado. Falávamos a exigência ética da responsabilidade radical e absoluta do cuidador por outrem (tomado, nesta discussão, como o usuário-louco-sujeito-alteridade), em que este último também sofre uma "afecção da alma", ou seja, é invariavelmente afetado pelo sofrer do outro, sendo afetado por uma subjetividade que o remete à sua própria humanidade. O outro que sofre é aquele "próximo que me recorda minha própria humanidade, minha finitude, minha miséria, minha solidão, minha morte" (Freire, 2008, p. 23).

Com base nisso, chegamos à inferência de que estamos por demais afastados, na vida tardo-moderna, dessa subjetividade que tem como constituição básica ser por e para outrem. Essa constatação traz, indubitavelmente, implicações ímpares para o dispositivo Caps, que tem a alteridade-loucura como sujeito-alvo de suas ações.

Essa alteridade não pode, portanto, estar submetida à mesma ética indolor das sociedades pós-moralistas, mas, ao contrário, exige necessariamente uma nova ética ancorada na afetação pela dor do outro. Os Caps, ao se questionarem sobre seus próprios saberes e fazeres, acabarão por compreenderem as contradições que lhe são inerentes, por criarem novas práticas que possam ir além da obviedade (da institucionalização, da patologização do sofrimento, da medicalização como único ou mais eficaz recurso terapêutico), enfim, por aproximarem-se da alteridade de tal modo a dar-lhe as respostas mais condizentes com o seu sofrimento.

Destarte, há que se tomar como referência a radicalidade ética de uma escuta complexa, absoluta e inclusiva da alteridade, não para que se criem idealizações e utopias de supressão de carências, de tamponamento de faltas, da resposta imediata às necessidades individualistas de outrem, mas para que se possa, de fato, enxergar os sujeitos que se apresentam diante de nós com seus novos modos de sofrer e adoecer, cujas subjetividades (produtos e ao mesmo tempo produtoras do contexto tardo-moderno) nos comunicam, em última instância, o impacto impiedoso do alheamento à alteridade na vida individual e coletiva. 


\section{Referências}

Alencar, H. F. \& Freire, J. C. (2007). O lugar da alteridade na Psicologia ambiental. Revista Mal-estar e subjetividade, 2 (6), 305-328.

Benasayag, M. (2005). L'Epoca delle passioni tristi. Milão: Feltrinelli Editore.

Benasayag, M. (2009). Sofrimento psíquico contemporâneo: construindo novos paradigmas. Conferência, 2 Seminário Internacional de Intercâmbio em práticas de saúde mental. Fortaleza.

Benasayag, M. (2010). O sofrimento psíquico na idade da técnica. Conferência, 28 Congresso Brasileiro de Psiquiatria. Fortaleza.

Betto, F., Barba, E. \& Costa, J. F. (1997). Ética. Rio de Janeiro: Garamond.

Birman, J. (2003). Dor e sofrimento num mundo sem mediação. Estados gerais da psicanálise, 2 Encontro Mundial. Rio de Janeiro.

Caponi, S. (2009). Michel Foucault e a persistência do poder psiquiátrico. Revista Ciência e Saúde Coletiva, 1 (14), 95-103.

Carvalho, L. B., Bosi, M. L. M. \& FREIRE, J. C. (2008). Dimensão ética do cuidado em saúde mental na rede pública de serviços. Revista de Saúde Pública, 4 (42), 700-706.

Figueiredo, L. C. M. (1995). Revisitando as psicologias: da epistemologia à ética nas práticas e discursos. Petrópolis: Vozes.

Freire, J. C. (2001). As psicologias na modernidade tardia: o lugar vacante do outro. Psicologia USP, 2 (12), 73-94.

Freire, J. C. (2002). O lugar do outro na modernidade tardia. São Paulo: Annablume; Fortaleza: Secult.

Freire, J. C. (2003). A Psicologia a serviço do Outro. Psicologia Ciência e Profissão, 4 (23), 12-15.

Freire, J. C. (2008). Cuidar da saúde do outro como dimensão ética. In: Teixeira, L. C. \& Buscher-Maluschke (orgs.). Os sofrimentos e seus destinos: psicologia, psicanálise e políticas de saúde. (pp. 19-30). Brasília: Universo.

Freire, J. C. \& Moreira, V. (2003). Psicopatologia e religiosidade no lugar do outro: uma escuta levinasiana. Psicologia em Estudo, 2 (8), 93-98. 
Gadamer, H. G. (2006). O caráter oculto da saúde. Petrópolis: Vozes.

Giddens, A. (2002). Modernidade e identidade. Rio de Janeiro: Jorge Zahar.

Hirdes, A. (2009). A reforma psiquiátrica no Brasil: uma (re)visão. Revista Ciência \& Saúde Coletiva, 1 (14), 297-305.

Homem, M. L. (2003). Entre próteses e prozacs: o sujeito contemporâneo imerso na descartabilidade da sociedade de consumo. Estados gerais da psicanálise: 2 Encontro Mundial. Rio de Janeiro.

Kristeva, J. (2002). As novas doenças da alma. Rio de Janeiro: Rocco.

Lemos, P. M. \& Cavalcante Júnior, F. S. (2009). Psicologia de orientação positiva: uma proposta de intervenção no trabalho com grupos em saúde mental. Revista Ciência e Saúde Coletiva, 1 (14), 233-242.

Lévinas, E. (1980). Totalidade e infinito. Lisboa: Ediçôes 70.

Lipovetsky, G. (2005). A sociedade pós-moralista: o crepúsculo do dever e a ética indolor dos novos tempos democráticos. São Paulo: Manole.

Lipovetsky, G. (2007). A sociedade da decepção. São Paulo: Manole.

Moreira, V. (2004). O método fenomenológico de Merleau-Ponty como ferramenta crítica na pesquisa em psicopatologia. Psicologia: Reflexão e Crítica, 3 (17), 447-456.

Ribeiro, S. L. (2004). A criação do Centro de Atenção Psicossocial Espaço Vivo. Psicologia Ciência e Profissão, 3 (24), 92-99.

Sloan, T. \& Moreira, V. (2002). Personalidade, ideologia e psicopatologia critica. São Paulo: Escuta.

Torre, E. H. G. \& Amarante, P. (2001). Protagonismo e subjetividade: a construção coletiva no campo da saúde mental. Ciência \& Saúde Coletiva, 1 (6), 73-85. 